\title{
Expression Pattern of Basal Markers in Human Dental Pulp Stem Cells and Tissue
}

\author{
W. Martens ${ }^{\mathrm{a}} \quad$ E. Wolfs ${ }^{\mathrm{b}} \quad$ T. Struys $^{\mathrm{a}} \quad$ C. Politis $^{\mathrm{a}, \mathrm{c}} \quad$ A. Bronckaers ${ }^{\mathrm{a}} \quad$ I. Lambrichts $^{\mathrm{a}}$ \\ ${ }^{a}$ Laboratory of Histology, Biomedical Research Institute, Universiteit Hasselt, Diepenbeek, ${ }^{\mathrm{b}}$ Division of Nuclear \\ Medicine, Department of Medical Diagnostic Sciences, Katholieke Universiteit Leuven, Leuven, and ${ }^{\mathrm{C} D e p a r t m e n t}$ \\ of Maxillo-Facial Surgery, Hospital of East Limburg, Genk, Belgium
}

\section{Key Words}

Dental pulp stem cells $\cdot$ Mesenchymal markers $\cdot$ Neural markers $\cdot$ Stem cell niche

\begin{abstract}
Dental pulp stem cells (DPSC) have been characterized as a multipotent stem cell population, with the ability to differentiate into mesodermal and neural cell lineages. Although 'de novo' expression of neural markers after differentiation is mostly considered as proof of differentiation, expression of these markers in undifferentiated DPSC is not well described. Therefore, an immunocytochemical analysis was performed to evaluate the neural marker expression of undifferentiated human DPSC (hDPSC) in in vitro cultures. Undifferentiated hDPSC uniformly expressed neural markers $\beta$-III-tubulin, S100 protein and synaptophysin. A subset of the population showed a positive immune-reactivity for galactocerebroside, neurofilament and nerve growth factor receptor p75. Furthermore, the location of possible stem cell niches, present in young dental pulp tissue, was determined by means of immunohistochemistry based on mesenchymal and neural marker expression. The results demonstrated the presence of a perivascular niche and a second stem cell niche at the cervical area. In adult dental pulp, only a perivascular niche could be observed. Based on the expression of neural
\end{abstract}

markers in naïve DPSC, it has to be taken into account that not only the marker expression upon neural differentiation must be analyzed, but an ultrastructural analysis of the morphological changes and functional studies must also be performed to confirm a successful differentiation.

Copyright $\odot 2012$ S. Karger AG, Basel

\section{Introduction}

In the adult organism, most tissues and organs contain a small population of cells, adult (mesenchymal) stem cells, which maintain the stem cell characteristics of selfrenewal and differentiation potential. By means of differ-

\section{Abbreviations used in this paper}

\begin{tabular}{ll}
\hline FCS & fetal calf serum \\
GalC & galactocerebroside \\
GFAP & glial fibrillary acidic protein \\
(h)DPSC & (human) dental pulp stem cells \\
MBP & myelin basic protein \\
MSC & mesenchymal stem cells \\
NF-H & neurofilament heavy chain \\
NGFR & nerve growth factor receptor \\
\hline
\end{tabular}

\section{KARGER}

Fax +4161306 1234

E-Mail karger@karger.ch

www.karger.com
(C) 2012 S. Karger AG, Basel

$1422-6405 / 12 / 1966-0490 \$ 38.00 / 0$

Accessible online at:

www.karger.com/cto
Dr. Wendy Martens

Biomedical Research Institute, Laboratory of Histology, Hasselt University

Campus Diepenbeek, Agoralaan, Building C, Office C011

BE-3590 Diepenbeek (Belgium)

Tel. +32 1126 9221, E-Mail wendy.martens@ uhasselt.be 
entiation, more committed progenitor cells can be generated along multiple lineages [Weissman, 2000]. Overall, adult stem cells remain quiescent within the adult tissue, but they are able to respond to injury and play an essential role in tissue repair processes. The maintenance and regulation of a quiescent stem cell population is tightly controlled by the local microenvironment of the host tissue.

Recently, it has been confirmed that a stem cell population is present inside the dental pulp. Evidence can be found in a study from Tecles et al. [2005] in which a migration of cells from perivascular regions was observed after pulp-capping procedures. These migrating cells played a role in reparative dentinogenesis and dentin bridge formation. Migration of stem cells to the site of injury for differentiation into odontoblast-like cells is an important event for cell recruitment during regeneration [Tecles et al., 2005; Sloan and Smith, 2007]. Another attempt to identify a stem cell niche inside dental pulp tissue was performed via immunohistochemical analysis in situ. By using a combination of markers (stem cell marker Stro-1, the perivascular cell marker CD146, alpha smooth-muscle actin and the pericyte-associated antigen 3G5) it was suggested that a population of dental pulp stem cells (DPSC) may reside in the perivascular niche within the adult pulp [Shi and Gronthos, 2003; Shi et al., 2005; Sloan and Smith, 2007]. However, further research is necessary to determine if other stem cell niches could be present within dental pulp tissue.

Several stem cell populations residing in dental tissues have been identified during the last 10 years. Gronthos et al. [2000] were the first to isolate and characterize the DPSC from human dental pulp tissue. Other stem cell populations in the tooth and surrounding tissues have been characterized since: periodontal ligament stem cells, stem cells from human exfoliated deciduous teeth, stem cells from apical papilla and dental follicle precursor cells [Miura et al., 2003; Seo et al., 2004; Morsczeck et al., 2005; Sonoyama et al., 2006]. DPSC are described as being a highly clonogenic and proliferative adult stem cell type with the capability of forming a dentin-pulp-like complex in vitro and in vivo [Gronthos et al., 2000; 2002]. They are an adherent fibroblast-like cell type, expressing commonly used mesenchymal stem cell markers such as CD29, CD44, CD105, CD146 and Stro-1. After induction with the appropriate media, DPSC possess a multilineage differentiation potential towards adipogenic, chondrogenic and osteogenic lineages [Struys et al., 2010]. Furthermore, differentiation into odontogenic, myogenic, angiogenic and neurogenic lineages in vitro and in vivo have been described [Gronthos et al.,
2000; Nosrat et al., 2004; Laino et al., 2005; d'Aquino et al., 2007; Arthur et al., 2008; Huang et al., 2008; Stevens et al., 2008; Karaoz et al., 2010]. A recent study shows that human DPSC (hDPSC) are able to differentiate in vitro into odontoblast-like cells producing a mineralized extracellular matrix possessing the molecular and mineral characteristics of dentin in vivo [About et al., 2000]. Since DPSC can be easily isolated and expanded in vitro and they are able to undergo differentiation into several lineages, they are a very promising stem cell population for future regeneration studies. Furthermore, human third molars are frequently removed for orthodontic or therapeutic reasons, being an easily accessible source of adult stem cells.

Before investigating the multilineage differentiation potential of DPSC, an overview of marker expression in undifferentiated DPSC is indispensable. Most studies analyze the expression of specific markers to assess the success of differentiation. During the last several years, the neural differentiation potential of mesenchymal stem cells has been widely investigated in order to find new stem-cell-based therapies in central and/or peripheral nervous disorders. DPSC are much like mesenchymal stem cells (MSC) and their multilineage differentiation potential and easy accessibility make them good candidates for cellular-based therapies. However, little is known about the basal expression levels of mesenchymal and neural marker in undifferentiated DPSC. Therefore, this study will focus on the expression of mesenchymal and neural markers in undifferentiated/naïve hDPSC both in vitro and in situ.

\section{Materials and Methods}

\section{Isolation and Cell Culture of Stem Cells from Dental Pulp}

Tissue

Normal human third molars were collected from patients (18-24 years old) at the Ziekenhuis Oost Limburg, Genk, Belgium with the patients' informed consent. Teeth were fractured mechanically and pulp tissue was isolated and collected in culture medium consisting of alpha Minimal Essential Medium (GIBCO Invitrogen Corp., Paisley, Scotland, UK) supplemented with $10 \%$ heat-inactivated fetal calf serum (FCS) (Biochrom AG, Berlin, Germany), $2 \mathrm{~mm}$ L-glutamine, $100 \mathrm{U} / \mathrm{ml}$ penicillin and $100 \mu \mathrm{g} / \mathrm{ml}$ streptomycin (GIBCO Invitrogen Corp.). Dental pulp was cut into pieces of $1 \mathrm{~mm}^{3}$, transferred to a 6-well plate containing culture medium and cultured via the explant method. The explants were kept in culture for 14 days to allow cells to grow out of the explants. Cells were cultured at $37^{\circ} \mathrm{C}$ in a humidified atmosphere containing $5 \% \mathrm{CO}_{2}$ with a change of medium twice a week. After 14-21 days, confluency was reached and cells were subcultured. 


\section{Immunocytochemistry}

To determine the expression profile of mesenchymal and neural markers in DPSC cultures, cells of passage 2-3 were seeded onto glass coverslips $\left(5,000\right.$ cells $\left./ \mathrm{cm}^{2}\right)$ and stained with the peroxidase-based EnVision System ${ }^{\circledR}$ (DakoCytomation, Glostrup, Denmark). The expression of commonly used mesenchymal markers (CD29, CD44, CD105, CD117, CD146 and Stro-1), early neural markers (nestin and vimentin), neuronal markers [ $\beta$-IIItubulin, nerve growth factor receptor p75 (NGFRp75), neurofilament heavy chain (NF-H) and synaptophysin], oligodendroglial markers [galactocerebroside (GalC) and myelin basic protein $(\mathrm{MBP})$ ] and astroglial markers [S100 protein and glial fibrillary acidic protein (GFAP)] was evaluated. When confluent, cells were fixed with paraformaldehyde $4 \%$ for $20 \mathrm{~min}$ and washed with PBS. When necessary, cells were permeabilized with Triton-X $0.05 \%$ for $30 \mathrm{~min}$ at $4^{\circ} \mathrm{C}$ and washed with PBS. To block nonspecific binding sites, cells were incubated with $10 \%$ normal goat serum or normal donkey serum at room temperature for $20 \mathrm{~min}$. After washing with PBS, cells were incubated with primary antibody (table 1) for $1 \mathrm{~h}$, followed by incubation with goat antimouse, goat anti-rabbit, or donkey anti-goat horseradish peroxidase-conjugated secondary antibodies for $30 \mathrm{~min}$. To visualize the peroxidase, diaminobenzidine chromogenic substrate was used. Cells were counterstained with Mayer's hematoxylin and mounted using an aqueous mounting medium (Aquatex; Merck, Darmstadt, Germany). The immune-reactivity of the cells was observed using a photomicroscope equipped with an automated camera (Nikon Eclipse 80i; Nikon Co., Japan).

\section{Fluorescent-Activated Cell Sorting Analysis}

Cells at passage $2-3$ were seeded in $25-\mathrm{cm}^{2}$ culture flasks and were harvested when $70-80 \%$ confluency was reached. Cells were first fixed and then permeabilized with the cytofix/cytoperm kit (Becton-Dickinson, San Jose, Calif., USA) according to the protocol provided by the manufacturer; 50,000 cells were then washed once with PBS containing 2\% FCS and were incubated with primary antibody (table 1) for $60 \mathrm{~min}$ at room temperature. As a negative control for nonspecific background staining, appropriate isotype controls were also included in the study. Thereafter, the cells were washed 3 times with PBS and incubated with secondary antibody PE-labeled anti-mouse IgG (Invitrogen) for $30 \mathrm{~min}$ at room temperature. Samples were analyzed on a FACScalibur flow cytometer equipped with CellQuest software (Becton-Dickinson). Ten thousand cells were included in the study.

\section{Immunohistochemistry}

Immunohistochemical analysis was performed on young dental pulp tissue using an indirect visualization system, based on a peroxidase-labeled polymer (Dako EnVision System). Young dental pulp tissue was isolated from teeth showing less than 50\% root formation. After fixation, paraffin-embedded sections $(7 \mu \mathrm{m})$ were deparaffinized and then microwaved in $10 \mathrm{~mm}$ citrate buffer $\mathrm{pH} 6.0$ and endogenous peroxidase activity was quenched with $0.5 \% \mathrm{H}_{2} \mathrm{O}_{2}$. Nonspecific binding sites were blocked with $10 \%$ normal goat serum. Sections were then stained with mouse or rabbit primary antibodies for $1 \mathrm{~h}$ (table 1 ) followed by incubation with a peroxidase-labelled polymer conjugated to a goat anti-mouse or goat anti-rabbit secondary antibody for $30 \mathrm{~min}$ and subsequently visualized using diaminobenzidine chromogenic substrate. Sections were counterstained with Mayer's hematoxylin, cover-
Table 1. Primary antibodies for immunocytochemistry and immunohistochemistry

\begin{tabular}{|c|c|c|c|}
\hline & Species & Dilution & Company \\
\hline \multicolumn{4}{|l|}{ MSC markers } \\
\hline CD29 & mouse & $1: 35$ & Abcam \\
\hline CD44 & mouse & $1: 200$ & Abcam \\
\hline CD105 & mouse & $1: 100$ & Abcam \\
\hline CD117 & rabbit & $1: 100$ & Santa Cruz \\
\hline CD146 & rabbit & r.t.u. & Abcam \\
\hline Stro-1 & mouse & $1: 50$ & R\&D systems \\
\hline \multicolumn{4}{|l|}{ Neural markers } \\
\hline$\beta$-III-tubulin & mouse & $1: 2000$ & Sigma Aldrich \\
\hline GalC & mouse & $1: 20$ & $\begin{array}{l}\text { Dr. V.W. Yong Cal- } \\
\text { gary }\end{array}$ \\
\hline GFAP & mouse & $1: 200$ & NovoCastra \\
\hline NGFRp75 & mouse & $1: 50$ & Dakocytomation \\
\hline MBP & mouse & $1: 200$ & Serotec \\
\hline NF-H & mouse & $1: 100$ & Dakocytomation \\
\hline S100 & rabbit & $1: 400$ & Dakocytomation \\
\hline Synaptophysin & mouse & $1: 20$ & Dakocytomation \\
\hline \multicolumn{4}{|l|}{ Other markers } \\
\hline Cytokeratin & mouse & r.t.u. & Dakocytomation \\
\hline Nestin & mouse & $1: 500$ & Chemicon \\
\hline Vimentin & mouse & $1: 500$ & Dakocytomation \\
\hline
\end{tabular}

Table 2. Composition of PCR reaction mix

PCR mix per sample, $\mu \mathrm{l}$

\begin{tabular}{ll}
\hline 10× PCR buffer & 2.5 \\
Forward primer, $25 \mu \mathrm{M}$ & 1 \\
Reverse primer, $25 \mu \mathrm{M}$ & 1 \\
dNTPs, $2 \mathrm{mM}$ & 0.25 \\
Taq polymerase, $1 \mathrm{U} / \mu \mathrm{l}$ & 0.75 \\
MilliQ & 19.1 \\
cDNA & 1 \\
\hline
\end{tabular}

slipped with an aqueous mounting medium and examined using a photomicroscope equipped with an automated camera (Nikon Eclipse 80i; Nikon Co.).

\section{RNA Extraction - cDNA Synthesis - RT- PCR}

Total RNA of hDPSC from passage 2 was isolated using the RNeasy Plus Mini kit (Qiagen, Venlo, The Netherlands) following the manufacturer's protocol. This kit ensures additional elimination of genomic DNA. The concentration and purity of total RNA was determined by measuring the optical density at $260 \mathrm{~nm}$ and the $260 \mathrm{~nm} / 280 \mathrm{~nm}$ ratio using the NanoDrop ND-1000 spectrophotometer (Thermo Fisher Scientific, Waltham, Mass., USA). 
Table 3. Primer sequences for RT-PCR

\begin{tabular}{|c|c|c|c|c|}
\hline Gene & Forward primer $\left(5^{\prime}-3^{\prime}\right)$ & Reverse primer $\left(5^{\prime}-3^{\prime}\right)$ & $\begin{array}{l}\mathrm{Tm} \\
{ }^{\circ} \mathrm{C}\end{array}$ & $\begin{array}{l}\text { Product } \\
\text { length, bp }\end{array}$ \\
\hline \multicolumn{5}{|l|}{ Neural markers } \\
\hline GalC & GCC-AAG-CGT-TAC-CAT-GAT-TT & GCA-GAG-ATG-GAC-TCC-CAG-AG & 58 & 161 \\
\hline GFAP & GCC-AAG-CCA-GAC-CTC-ACC-GC & GTG-TCC-AGG-CTG-GTT-TCT-CGA-ATC & 60 & 509 \\
\hline MBP & CCC-CGT-AGT-CCA-CTT-CTT-CA & TCC-CTT-GAA-TCC-CTT-GTG-AG & 56 & 178 \\
\hline S100 & TGA-TCC-AGA-AGG-AGC-TCA-CC & CCC-TTG-AGG-GCT-TCA-TTG-TA & 56 & 160 \\
\hline \multicolumn{5}{|l|}{ Other markers } \\
\hline Nestin & AAC-AGC-GAC-GGA-GGT-CTC-TA & TTC-TCT-TGT-CCC-GCA-GAC-TT & 56 & 220 \\
\hline Vimentin & GAG-AAC-TTT-GCC-GTT-GAA-GC & TCC-AGC-AGC-TTC-CTG-TAG-GT & 56 & 170 \\
\hline \multicolumn{5}{|l|}{ Housekeeping genes } \\
\hline$\beta$-Actin & AAA-TCT-GGC-ACC-ACA-CCT-TC & AGA-GGC-GTA-CAG-GGA-TAG-CA & 56 & 185 \\
\hline
\end{tabular}

700 ng of total RNA was reverse transcribed into cDNA according to the manufacturer's instructions for the Reverse Transcription System (Promega, Leiden, The Netherlands). Samples were stored at $-80^{\circ} \mathrm{C}$ for further analysis. RT-PCR was performed by means of Taq DNA polymerase (1 U/ $\mu$ l; Roche Diagnostics, Vilvoorde, Belgium) (table 2). PCR reactions were performed by a BioRad Thermal cycler (Biorad, Hercules, Calif., USA) under the following conditions: a denaturation step at $94^{\circ} \mathrm{C}$ for $5 \mathrm{~min}$ was followed by amplification over 35 cycles of denaturation $\left(94^{\circ} \mathrm{C}\right.$ for $\left.1 \mathrm{~min}\right)$, annealing (temperature dependent on the primers for $60 \mathrm{~s}$ ) and elongation $\left(72^{\circ} \mathrm{C}\right.$ for $\left.2 \mathrm{~min}\right)$. Sequences of the primers (Eurogentec S.A. Seraing, Belgium) can be found in table 3. The housekeeping genes b-actin, GusB and b2-microglobulin were used as a control for the PCR reaction. PCR products were separated on a $1.5 \%$ agarose gel (Invitrogen, Merelbeke, Belgium) and visualized with gel red.

\section{Results}

Characterization of Human Dental Pulp Stem Cells

Cultures of hDPSC were isolated via the explant culture methods, in which cells were allowed to grow out of the explants (fig. 1a). When confluency was reached, hDPSC were subcultured. In vitro, hDPSC comprised a heterogeneous cell population containing cells with a polygonal or spindle-shaped (fibroblast-like) morphology. Cells were adherent to a plastic surface and formed colonies in vitro (fig. $1 \mathrm{~b}-\mathrm{d}$ ). Furthermore, hDPSC were capable of differentiating into adipocytes, chondrocytes and osteoblasts when grown under the appropriate culture conditions (data not shown).

Neural and MSC Markers in Dental Pulp Stem Cells and Tissue
To evaluate the expression pattern of classical mesenchymal surface markers in vitro, an immunocy tochemical staining for CD29, CD44, CD105, CD117, CD146 and Stro-1 was performed. hDPSC uniformly showed a positive immune-reactivity for these mesenchymal markers. However, Stro-1 expression was only found in a subset of the cell population. After manual counting, $5.8 \%$ of the cell population was Stro-1-positive (fig. $2 \mathrm{f}$, arrows).

Neural Marker Expression of Undifferentiated hDPSC

RT-PCR was performed to determine the transcript levels of neural markers in undifferentiated hDPSC. hDPSC were shown to possess neural genes $\beta$-III-tubulin, GalC, S100 and NF-H at the mRNA level. No transcripts of GFAP and MBP were detected in undifferentiated hDPSC (data not shown). Furthermore, levels of nestin and vimentin, which are early neural markers, were found (fig. 3B).

At the protein level, similar results were observed. Immunocytochemical analysis revealed that hDPSC stained uniformly for the neural markers $\beta$-III-tubulin, S100 and synaptophysin and for the early markers nestin and vimentin (fig. 3A: g, h). After manual counting, $4.07 \%$ of the cell population was NGFRp75-positive (fig. 3A: f, arrows). No GFAP and MBP expression was found (data not shown). Flow cytometric analysis of hDPSC confirmed that almost all hDPSC expressed $\beta$-III-tubulin, GalC, nestin and vimentin, while only $42.27 \%$ cells were positive for NF-H (fig. 3C). 
Fig. 1. Phase-contrast images of in vitro cultures of hDPSC. a hDPSC were cultured via the explant method. Cells grew out of pulp tissue explants on plastic substrates. b-d Isolated cells displayed a flattened polygonal morphology and were capable of forming colonies in vitro. a, b, d Scale bar $=200 \mu \mathrm{m}$. c Scale bar $=$ $50 \mu \mathrm{m}$.
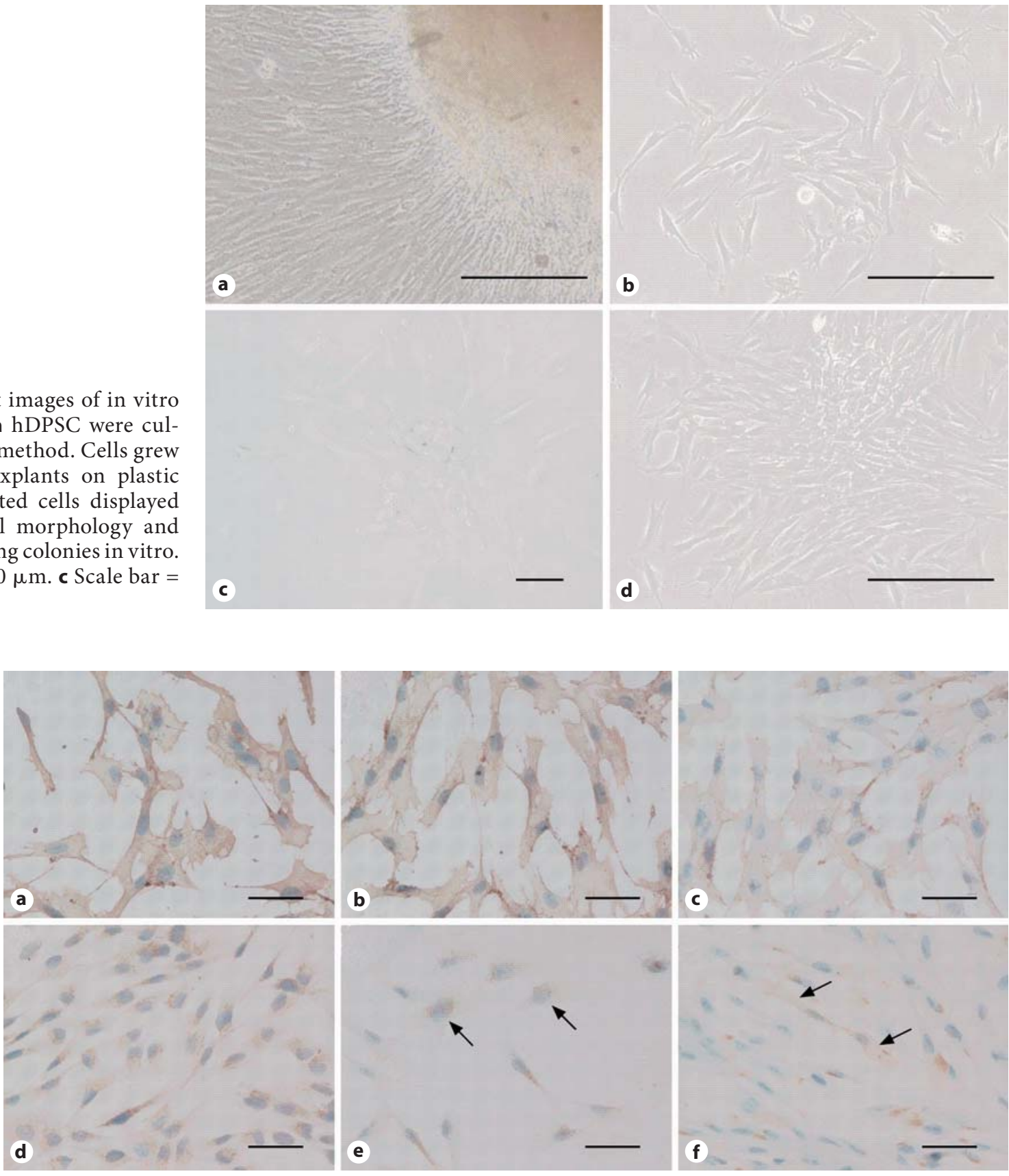

Fig. 2. Analysis of mesenchymal marker expression in undifferentiated hDPSC. a-e hDPSC stained uniformly for CD29, CD44, CD105, CD146 and CD117. f Stro-1 expression was only found in part of the population (5.8\%; SD 2.2\%). Scale bar $=50 \mu \mathrm{m}$.

Expression of Mesenchymal and Neural Markers in Dental Pulp Tissue - Immunohistochemical Analysis

Immunohistochemical stainings on human dental pulp tissue were performed to evaluate the expression pattern of mesenchymal and neural markers in young dental pulp tissue. Young dental pulp tissue was isolated from teeth showing less than $50 \%$ root formation. The mesenchymal markers CD29, CD44, CD117, CD146 and Stro-1 were expressed throughout the whole tissue with a more pronounced expression of CD29, CD44 and CD146 


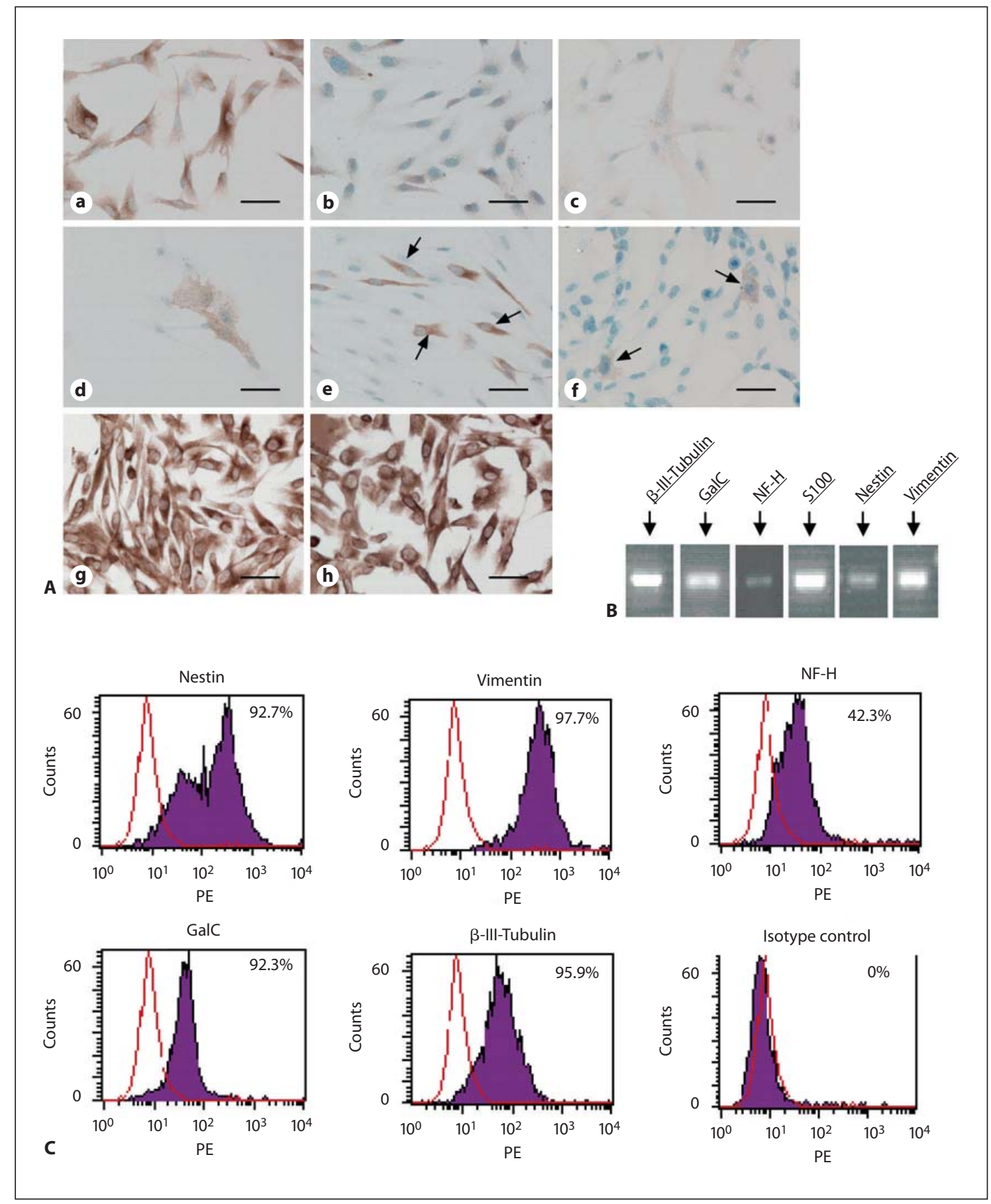

Fig. 3. Expression profile of neural markers. A Immunohistochemical staining of hDPSC. hDPSC stained uniformly for $\beta$-IIItubulin (a), S100 (b) and synaptophysin (c). Only a fraction of the cells expressed GalC (92.3\%) (d), neurofilament (42.27\%) (e) and NGFRp75 (4.07\%) (f). Nestin (g) and vimentin (h) expression was observed in all hDPSC. Scale bar $=50 \mu \mathrm{m}$. B Expression of neural genes at the mRNA levels in hDPSC. C Flow cytometric analysis of neurobasal marker expression in hDPSC. Red: isotype control. Purple: expression of the specific protein. Flow cytometric analysis confirmed that almost all hDPSC expressed $\beta$-III-tubulin, GalC, nestin and vimentin, while only $42.27 \%$ cells were positive for NF-H. 
at the cementum-enamel border and CD29+ cells at the apical region of the pulp tissue as shown in figure $4 \mathrm{a}-\mathrm{i}$. Furthermore, an increase of cells positively stained for CD29, CD44 and CD146 was observed at the cervical area towards the center of the tissue and towards the apical region of the dental pulp tissue. The pattern was most obvious after staining with anti-CD44 (fig. 4d). Upon staining with anti-CD105, a weak immune-reactivity was observed throughout the tissue (fig. 4l-m). In addition, dental pulp tissue was homogenously stained with antinestin, anti-vimentin and anti-S100 (fig. 5a-c). Cells positive for $\beta$-III-tubulin and NGFRp75 were mainly found at the subodontoblast zone. In the central part of the tissue, the expression of both markers was related to neural structures. Nerve fibers were also positively stained with anti-neurofilament, anti-MBP and anti-synaptophysin which was comparable with NGFRp75 staining (fig. 5dh). In contrast to the in vitro cultures of hDPSC, no GalC+ cells were observed in the dental pulp tissue. Furthermore, no GFAP+ cells could be observed in the tissue, which is consistent with no GFAP+ cells present in in vitro cultures. At the apical region of dental pulp tissue, fragments of epithelial cells were seen which stained positive for cytokeratin (data not shown).

\section{Discussion}

Based on their ease of isolation and expansion in vitro, and multilineage differentiation potential both in vitro and in vivo, hDPSC have become a very promising alternative source of MSC for future regeneration studies during the last 10 years. The results of this study, concerning the isolation method and morphological appearance of hDPSC in vitro, are comparable with a previous study of our group [Struys et al., 2010]. hDPSC cultured via the explant method were described as being an adherent colony-forming cell type with a fibroblast-like morphology. The expression of the mesenchymal surface markers CD29, CD44, CD105, CD146, CD117 and Stro-1 was found in undifferentiated hDPSC. Furthermore, hDPSC possessed the ability to differentiate into cells of adipogenic, chondrogenic and osteogenic lineages as previously described in our laboratory [Struys et al., 2010].

When investigating the neural differentiation potential of MSC, the success of differentiation is often based on the expression of certain neural markers like nestin, $\beta$-III-tubulin, neurofilament [Safford et al., 2002; Tropel et al., 2006; Alexanian et al., 2008; Arthur et al., 2008; Kiraly et al., 2009; Karaoz et al., 2010]. Although some neural markers (e.g. $\beta$-III-tubulin; fig. 5) are highly expressed in neural structures within the pulp tissue, expression of these markers was also observed in the in vitro cultures. Nevertheless, the basal levels of neural marker expression in undifferentiated cells must be taken into account. Depending on the composition of the culture media, certain markers could already be expressed by the naïve stem cells. The study of Blondheim et al. [2006] reported the expression of neural genes in undifferentiated bone marrow MSC. In the culture media used, a high percentage of FCS combined with horse serum and epidermal growth factor supplement was present, possibly leading to the expression of nestin and neurofilament in naïve bone marrow MSC [Blondheim et al., 2006]. In the present study, undifferentiated hDPSC uniformly expressed $\beta$-III-tubulin, S100, synaptophysin, nestin and vimentin. Furthermore, a high percentage of the cell culture showed a positive immune-reactivity for GalC and NF-H. Apart from the expression of neural markers by hDPSC, several studies report the production and secretion of neurotrophic factors brain-derived neurotrophic factor, glial cell line-derived neurotrophic factor and NGF [Nosrat et al., 2001; Nosrat et al., 2004; Arthur et al., 2008; Apel et al., 2009]. It must be taken into account that dental pulp is derived from neural crest tissue, giving a predisposition of differentiation towards neural lineages. Nevertheless, by using low-serum-containing media, the expression of certain neural markers was lost in naïve DPSC [Karbanova et al., 2011]. Depending on the differentiation potential investigated, a good consideration of medium composition is obligatory. Using high serum levels and/or growth factor supplements in basal culture media could lead to an early expression of neural markers in naïve MSC. In this study, the dental pulp tissue stained negative for GalC in contrast to hDPSC in vitro. During cell culture, growth media containing high levels of serum ( $10 \%$ FCS) were used which could lead to the expression of GalC in hDPSC in vitro. Most likely, growth factors present in the serum could induce the expression of GalC in certain cells. This leads to the conclusion that careful consideration of medium composition or cell culture conditions is indeed needed for differentiation studies as certain cell culture conditions may interfere with the differentiation potential of hDPSC. As this study clearly demonstrated that undifferentiated hDPSC expressed neural markers such as $\beta$-III-tubulin, nestin, S100, synaptophysin, nestin and vimentin, when cultured in $10 \%$ FCS, these markers can never be used to confirm neural or glial differentiation of hDPSC. Therefore, besides the evaluation of marker expression before and after 

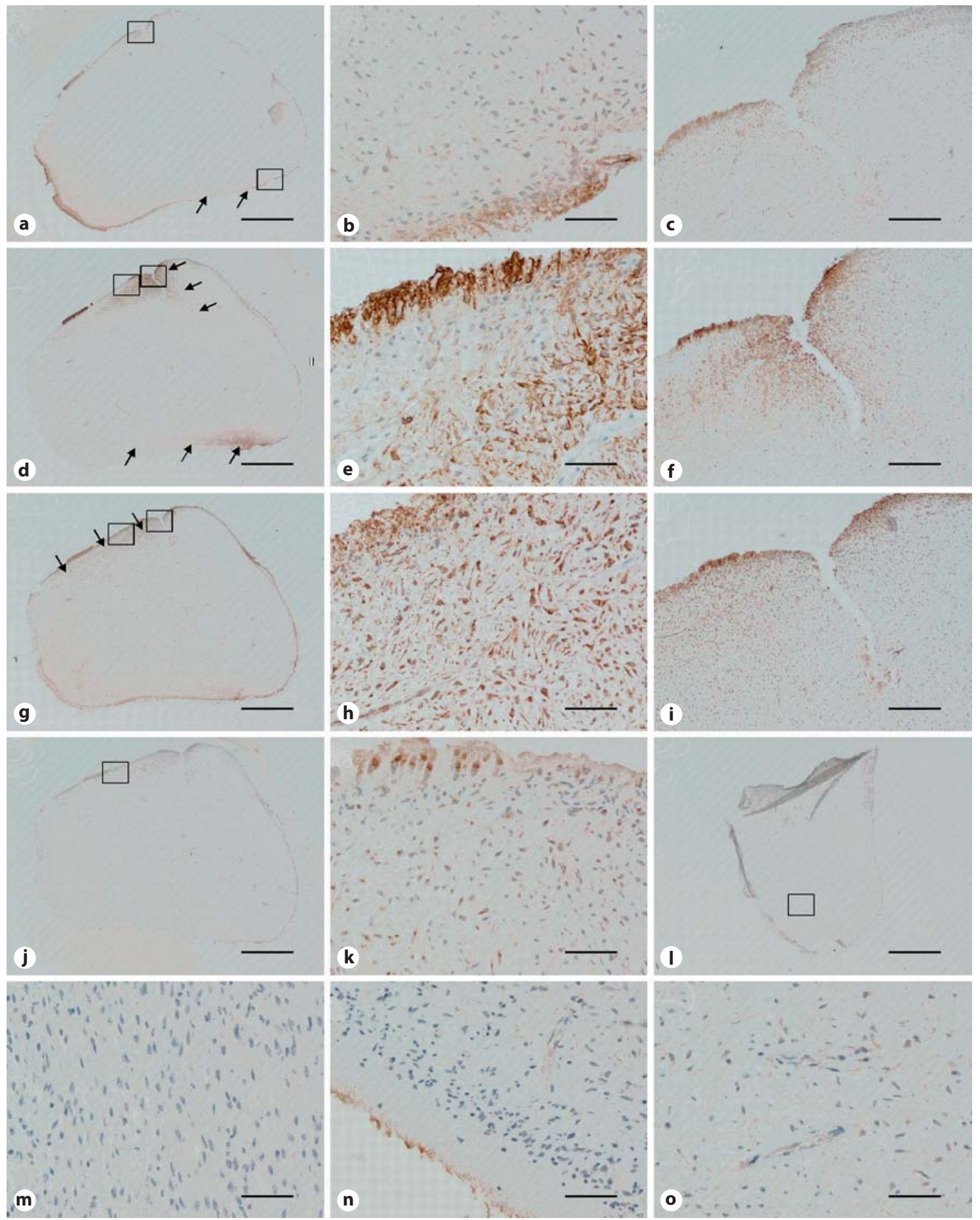

Fig. 4. Immunohistochemical staining of mesenchymal markers in human dental pulp tissue. Expression of the mesenchymal markers CD29 (a-c), CD44 (d-f), CD146 (g, i), CD117 (j, k), CD105 (I, m) and Stro-1 (n, o) was observed in dental pulp tissue. Arrows indicate a possible migration pattern (a, d, g). a, d, g, j, I Scale bar $=1,000 \mu \mathrm{m} . \mathbf{b}, \mathbf{e}, \mathbf{h}, \mathbf{k}, \mathbf{m}-\mathbf{o}$ Scale bar $=50 \mu \mathrm{m} . \mathbf{c}, \mathbf{f}, \mathbf{i}$ Scale bar $=200 \mu \mathrm{m}$. 
Fig. 5. Immunohistochemical staining of neural markers in human dental pulp tissue. A positive expression of the neural markers nestin (a), vimentin (b) and S100 (c) is found throughout the whole tissue. Expression of $\beta$-III-tubulin (d) and NGFRp75 (e) was observed at the subodontoblast zone. In the center of the tissue, the expression of both markers was related to neural structures. Nerve fibers were also immune-reactive for neurofilament (f), MBP (g) and synaptophysin (h). a-c, f-h Scale bar $=50 \mu \mathrm{m}$. d, e Scale bar $=200$ $\mu \mathrm{m}$.
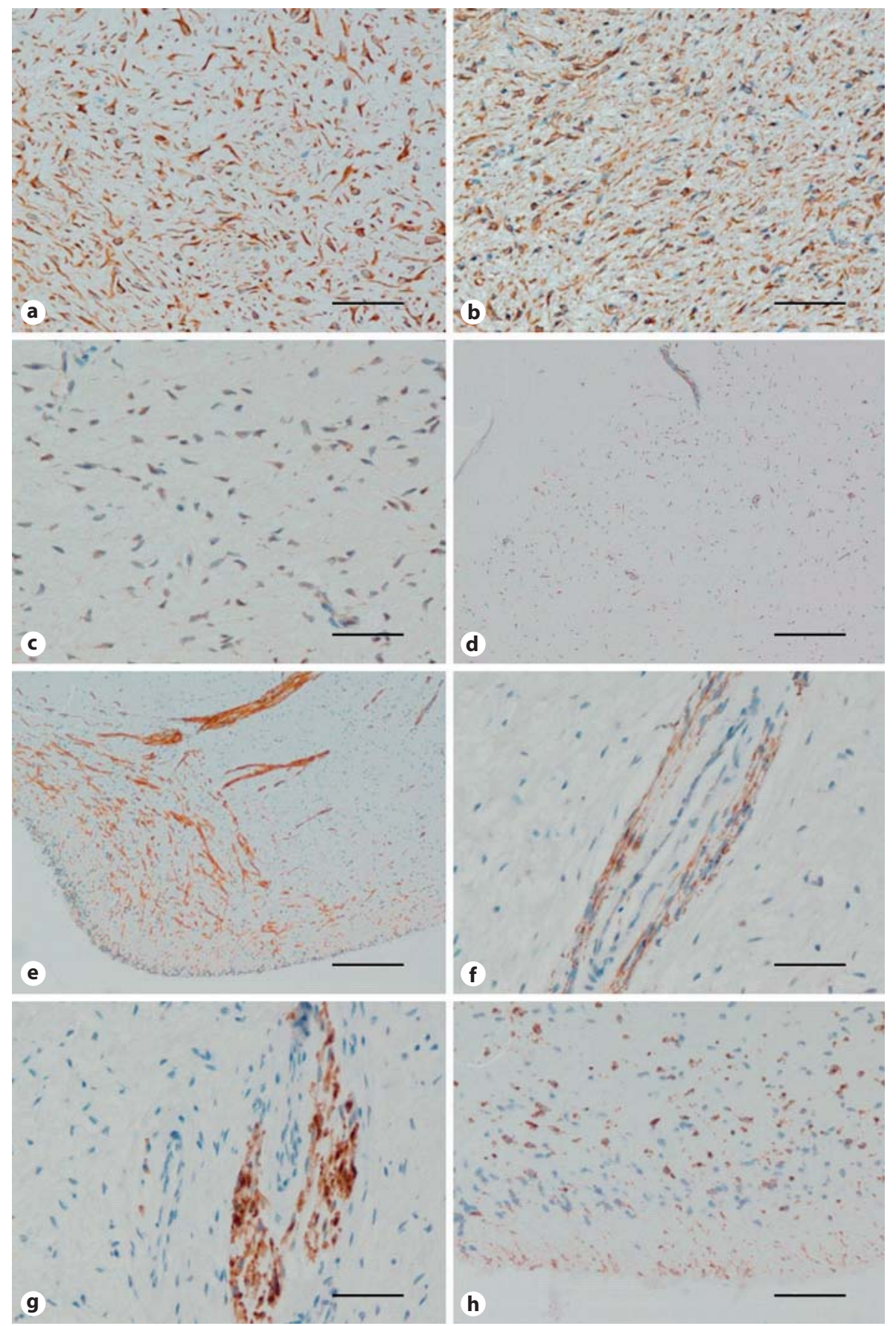

differentiation studies, an ultrastructural analysis of the morphological changes and/or functional studies must be included in the experiments to confirm a really successful differentiation.

Several studies report the presence of a perivascular niche of stem cells residing in the adult dental pulp [Shi and Gronthos, 2003; Tecles et al., 2005; Sloan and Smith,
2007]. By means of immunohistochemical analysis, the expression of various mesenchymal and neural markers was evaluated in young dental pulp tissue. Young dental pulp tissue was derived from teeth in a $<50 \%$ root formation stage. As young dental pulp tissue, still being an immature tissue, was used for the immunohistochemical analysis, an overall expression of nestin and vimentin 
was found. The results further demonstrated the presence of a perivascular stem cell niche and a second niche at the cementum-enamel border/cervical area. An increased amount of CD29+, CD44+ and CD146+ stained cells were observed from this cervical area towards the center of the pulp tissue and towards the apex. Although only a weak expression of CD105 was observed in our experiments, the study of Alongi et al. [2010] confirms our results in which a strong expression of CD105 was found in dental pulp tissue. Neural marker expression was mainly related to neural structures within the tissue. However, some cells residing in the subodontoblast zone stained positive for $\beta$-III-tubulin and NGFRp75. On the other hand, in adult pulp tissue, only a perivascular niche is present (data not shown). This leads to the conclusion that the niche at the cervical area is lost during maturation of the tissue. A possible explanation can be that this niche contains cells from the dental papilla which will migrate apically forming the apical papilla in a later stage. It is generally known that during tooth development, the dental papilla will contribute to tooth formation and converts to the pulp tissue inside the pulp chamber. As the root continues to develop, the location of the dental papilla becomes apical to the pulp tissue [Nanci, 2008]. A second explanation could be that being immature tissue, progenitor/stem cells are essential in the developmental processes of the tooth resulting in the presence of multiple niches including a stem cell niche at the cervical area.
Once the tooth is fully matured, progenitor/stem cells are only required after injury to play a role in tissue repair processes, leading to less stem cell niches being necessary. The presence of a perivascular niche in adult dental pulp tissue was confirmed by previous studies [Shi and Gronthos, 2003; Tecles et al., 2005; Sloan and Smith, 2007]. Moreover, by using a combination of specific markers, Karbanova et al. [2011] suggested the idea of multiple stem cell niches present within the dental pulp, containing distinct multipotent DPSC. Further research is necessary to identify the exact location of the niches which could be helpful in understanding if the isolated multipotent stem cells are derived from one highly proliferative multipotent stem cell population or from committed progenitors belonging to distinct lineages.

\section{Acknowledgements}

The authors of the manuscript are very grateful to Marc Jans and Jeanine Santermans for their dedicated technical assistance. A.B. received a postdoctoral grant from the Fonds voor Wetenschappelijk Onderzoek-Vlaanderen.

\section{Disclosure Statement}

The funders had no role in study design, data collection and analysis, the decision to publish or preparation of the manuscript.

\section{References}

About, I., M.J. Bottero, P. de Denato, J. Camps, J.C. Franquin, T.A. Mitsiadis (2000) Human dentin production in vitro. Exp Cell Res 258: 33-41.

Alexanian, A.R., D.J. Maiman, S.N. Kurpad, T.A. Gennarelli (2008) In vitro and in vivo characterization of neurally modified mesenchymal stem cells induced by epigenetic modifiers and neural stem cell environment. Stem Cells Dev 17: 1123-1130.

-Alongi, D.J., T. Yamaza, Y. Song, A.F. Fouad, E.E Romberg, S. Shi, R.S. Tuan, G.T. Huang (2010) Stem/progenitor cells from inflamed human dental pulp retain tissue regeneration potential. Regen Med 5: 617-631.

Apel, C., O.V. Forlenza, V.J. de Paula, L.L. Talib, B. Denecke, C.P. Eduardo, W.F. Gattaz (2009) The neuroprotective effect of dental pulp cells in models of Alzheimer's and Parkinson's disease. J Neural Transm 116: 71-78.

d'Aquino, R., A. Graziano, M. Sampaolesi, G. Laino, G. Pirozzi, A. De Rosa, G. Papaccio (2007) Human postnatal dental pulp cells co-differ- entiate into osteoblasts and endotheliocytes: a pivotal synergy leading to adult bone tissue formation. Cell Death Differ 14: 1162-1171.

-Arthur, A., G. Rychkov, S. Shi, S.A. Koblar, S. Gronthos (2008) Adult human dental pulp stem cells differentiate toward functionally active neurons under appropriate environmental cues. Stem Cells 26: 1787-1795.

Blondheim, N.R., Y.S. Levy, T. Ben-Zur, A. Burshtein, T. Cherlow, I. Kan, R. Barzilai, M. BahatStromza, Y. Barhum, S. Bulvik, E. Melamed, D. Offen (2006) Human mesenchymal stem cells express neural genes, suggesting a neural predisposition. Stem Cells Dev 15: 141-164.

Gronthos, S., J. Brahim, W. Li, L.W. Fisher, N. Cherman, A. Boyde, P. DenBesten, P.G. Robey, S. Shi (2002) Stem cell properties of human dental pulp stem cells. J Dental Res 81: 531-535.

Gronthos, S., M. Mankani, J. Brahim, P.G. Robey, S. Shi (2000) Postnatal human dental pulp stem cells (DPSCs) in vitro and in vivo. Proc Natl Acad Sci USA 97: 13625-13630.
Huang, G.T., W. Sonoyama, Y. Liu, H. Liu, S. Wang, S. Shi (2008) The hidden treasure in apical papilla: the potential role in pulp/dentin regeneration and bioroot engineering. J Endod 34: 645-651.

Karaoz, E., B.N. Dogan, A. Aksoy, G. Gacar, S. Akyuz, S. Ayhan, Z.S. Genc, S. Yuruker, G. Duruksu, P.C. Demircan, A.E. Sariboyaci (2010) Isolation and in vitro characterisation of dental pulp stem cells from natal teeth. Histochem Cell Biol 133: 95-112.

Karbanova, J., T. Soukup, J. Suchanek, R. Pytlik, D. Corbeil, J. Mokry (2011) Characterization of dental pulp stem cells from impacted third molars cultured in low serum-containing medium. Cells Tissues Organs 193: 344-365.

Kiraly, M., B. Porcsalmy, A. Pataki, K. Kadar, M. Jelitai, B. Molnar, P. Hermann, I. Gera, W.D. Grimm, B. Ganss, A. Zsembery, G. Varga (2009) Simultaneous PKC and cAMP activation induces differentiation of human dental pulp stem cells into functionally active neurons. Neurochem Int 55: 323-332. 
Laino, G., R. d'Aquino, A. Graziano, V. Lanza, F. Carinci, F. Naro, G. Pirozzi, G. Papaccio (2005) A new population of human adult dental pulp stem cells: a useful source of living autologous fibrous bone tissue (LAB). J Bone Miner Res 20: 1394-1402.

-Miura, M., S. Gronthos, M. Zhao, B. Lu, L.W. Fisher, P.G. Robey, S. Shi (2003) SHED: stem cells from human exfoliated deciduous teeth. Proc Natl Acad Sci USA 100: 5807-5812.

-Morsczeck, C., W. Gotz, J. Schierholz, F. Zeilhofer, U. Kuhn, C. Mohl, C. Sippel, K.H. Hoffmann (2005) Isolation of precursor cells (PCs) from human dental follicle of wisdom teeth. Matrix Biol 24: 155-165.

Nanci, A. (2008) Ten Cate's Oral Histology: Development, Structure, and Function. Philadelphia, Elsevier Health Sciences.

Nosrat, I.V., C.A. Smith, P. Mullally, L. Olson, C.A. Nosrat (2004) Dental pulp cells provide neurotrophic support for dopaminergic neurons and differentiate into neurons in vitro; implications for tissue engineering and repair in the nervous system. Eur J Neurosci 19: $2388-2398$.
Nosrat, I.V., J. Widenfalk, L. Olson, C.A. Nosrat (2001) Dental pulp cells produce neurotrophic factors, interact with trigeminal neurons in vitro, and rescue motoneurons after spinal cord injury. Dev Biol 238: 120 132.

Safford, K.M., K.C. Hicok, S.D. Safford, Y.D. Halvorsen, W.O. Wilkison, J.M. Gimble, H.E. Rice (2002) Neurogenic differentiation of murine and human adipose-derived stromal cells. Biochem Biophys Res Commun 294: 371-379.

Seo, B.M., M. Miura, S. Gronthos, P.M. Bartold, S. Batouli, J. Brahim, M. Young, P.G. Robey, C.Y. Wang, S. Shi (2004) Investigation of multipotent postnatal stem cells from human periodontal ligament. Lancet 364: 149155.

-Shi, S., P.M. Bartold, M. Miura, B.M. Seo, P.G. Robey, S. Gronthos (2005) The efficacy of mesenchymal stem cells to regenerate and repair dental structures. Orthod Craniofac Res 8: 191-199.

-Shi, S., S. Gronthos (2003) Perivascular niche of postnatal mesenchymal stem cells in human bone marrow and dental pulp. J Bone Miner Res 18: 696-704.

-Sloan, A.J., A.J. Smith (2007) Stem cells and the dental pulp: potential roles in dentine regeneration and repair. Oral Diseases 13: 151-157.

Sonoyama, W., Y. Liu, D. Fang, T. Yamaza, B.M. Seo, C. Zhang, H. Liu, S. Gronthos, C.Y. Wang, S. Wang, S. Shi (2006) Mesenchymal stem cell-mediated functional tooth regeneration in swine. PloS One 1: e79.
Stevens, A., T. Zuliani, C. Olejnik, H. LeRoy, H. Obriot, J. Kerr-Conte, P. Formstecher, Y. Bailliez, R.R. Polakowska (2008) Human dental pulp stem cells differentiate into neural crest-derived melanocytes and have label-retaining and sphere-forming abilities. Stem cells and development 17: 1175-1184.

Struys, T., M. Moreels, W. Martens, R. Donders, E. Wolfs, I. Lambrichts (2010) Ultrastructural and immunocytochemical analysis of multilineage differentiated human dental pulp- and umbilical cord-derived mesenchymal stem cells. Cells Tissues Organs 193: 366-378.

Tecles, O., P. Laurent, S. Zygouritsas, A.S. Burger, J. Camps, J. Dejou, I. About (2005) Activation of human dental pulp progenitor/stem cells in response to odontoblast injury. Arch Oral Biol 50: 103-108.

Tropel, P., N. Platet, J.C. Platel, D. Noel, M. Albrieux, A.L. Benabid, F. Berger (2006) Functional neuronal differentiation of bone marrow-derived mesenchymal stem cells. Stem Cells 24: 2868-2876.

Weissman, I.L. (2000) Stem cells: units of development, units of regeneration, and units in evolution. Cell 100: 157-168. 